Obere Extremität 2021 · 16:210-212

https://doi.org/10.1007/s11678-021-00632-1

Received: 23 December 2020

Accepted: 27 January 2021

Published online: 23 February 2021

(c) The Author(s) 2021

\author{
Marc Schnetzke ${ }^{1,2,3}$ (D) Markus Loew ${ }^{1} \cdot$ Sven Lichtenberg' \\ 'German Joint Centre Heidelberg, ATOS Clinic Heidelberg, Heidelberg, Germany \\ ${ }^{2}$ Clinic for Trauma and Orthopaedic Surgery at the University of Heidelberg, BG Trauma Center \\ Ludwigshafen, Ludwigshafen on the Rhine, Germany \\ ${ }^{3}$ Medizinische Fakultät Heidelberg der Universität Heidelberg, Heidelberg, Germany
}

\title{
Arthroscopic treatment of calcifying tendinitis
}

\section{Surgical procedure}

\section{Video online}

The online version of this article (https:// doi.org/10.1007/s11678-021-00632-1) contains the video: "Arthroscopic treatment of calcifying tendinitis." You will find the video at the end of the article as "Supplementary material." Video by courtesy of M. Schnetzke, M. Loew, and S. Lichtenberg, Atos Clinic Heidelberg, German Joint Centre Heidelberg, Germany; all rights reserved 2021.

\section{Background}

Calcifying tendinitis is one of the most frequent disorders in the area of the shoulder joint. The condition is characterized by an accumulation of calcium phosphate crystals in the insertion area of the rotator cuff tendons [2], of which the supraspinatus tendon is the most commonly involved. As described in the review by Loew et al. [3], calcifying tendinitis progresses in stages and can vary from mild asymptomatic disease courses over a number of years to acute painful exacerbations.

In symptomatic calcifying tendinitis, conservative therapy is the method of choice [5]. Patients who suffer from persistent symptoms and who experience no improvement from conservative therapy can benefit from surgery. In this article, we present a typical case of a 56-yearold female patient with pain on loadbearing in the area of the right shoulder for 3 years (• Fig. 1). Despite shockwave therapy and analgesics, no improvement in the symptoms had occurred.
In preparation for surgery, current radiographs ( $<6$ weeks old) should be taken to be able to localize the calcified focus exactlyand, more importantly, to document that the calcified focus has not dissolved in the intervening period. Frequently, the indication for surgical removal of the calcified focus is established in a phase of acute painful exacerbation. However, an acute increase in pain is often the sign of spontaneous dissolution of a calcified focus.

The patient is placed in the beach chair position and the anatomical landmarks are marked before the start of arthroscopy. The camera is introduced into the joint via the standard dorsal portal and diagnostic arthroscopy is performed.

After the end of diagnostic arthroscopy, the camera is introduced into the subacromial space. The synovial resector is advanced alternately with the thermal probe via an additional standard anterolateral portal and bursectomy is performed. In this way, the rotator cuff is completely freed from the inflamed bursa tissue and visualized. Because of the bursitis that is usually present, the tissue is hyperemic and small hemorrhages that interfere with visualization can constantly occur. Gentle hemostasis is therefore essential for a correct procedure.

After the bursa has been completely removed from the rotator cuff, the latter is inspected for areas of visible protrusions, neovascularity, or calcium deposits.
In the area of suspected calcium deposition, the rotator cuff is perforated with a hollow needle. Calcium fragments in the area of the needle tip confirm the correct localization of the calcified focus. The rotator cuff tendon is then opened with a scalpel in line with the fibers. The released calcium may resemble either "toothpaste" or "chalk dust." The intratendinous calcium is removed alternately with a sharp curette and synovial resection. The subacromially released calcium is completely removed with the synovial resection.

Removal of the calcium deposit generates a cavity in the rotator cuff tendon. This cavity should be carefully inspected and any calcium residues still present should be removed. The authors then recommend intraoperative radio-

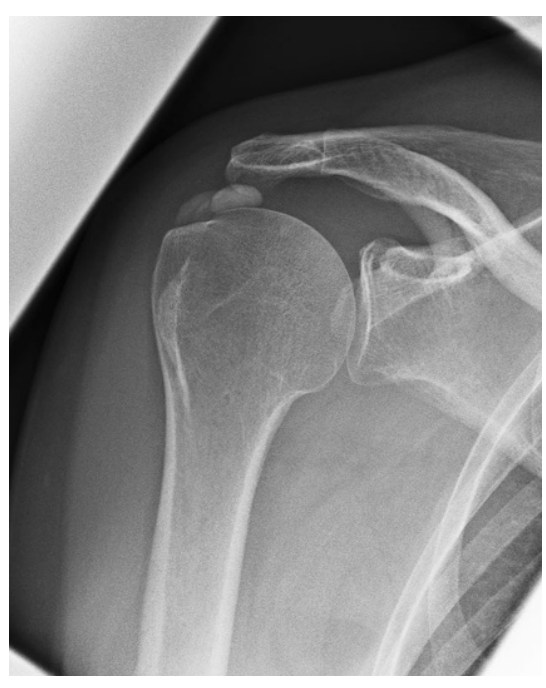

Fig. $1 \Delta$ Imaging of a 56-year-old female patient with treatment-refractory symptoms over a period of 3 years without signs of dissolution of the calcified focus 


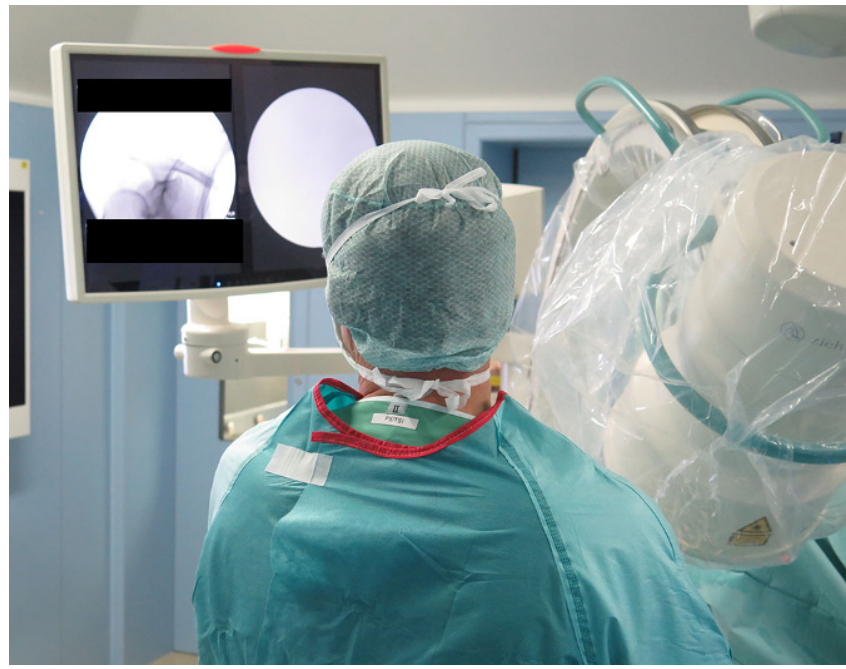

Fig. $2<$ Intraoperative fluoroscopy confirms complete removal of the intratendinous calcium deposit graphy to identify any further existing calcium deposits. Moreover, intraoperative radiography is useful for documenting complete evacuation of the calcium deposit (• Fig. 2).

From the authors' point of view, if a major defect of the rotator cuff is present $(>0.5 \mathrm{~cm}$ of the tendon diameter), then a tendon repair is necessary. Tendon reconstruction is performed according to the same principles as for a normal tendon tear. In most cases a side-to-side suture in the area of the opened tendon is possible.

Once the tendon suture is completed, the arthroscopy is finished and a sterile dressing is applied. Immobilization is generally not necessary. In the case of more serious defects of the rotator cuff or coexisting pathologies, e.g., of the long biceps tendon, immobilization is adapted accordingly.

\section{Discussion}

The cause of calcium deposits in the area of the rotator cuff tendons has not been established to date. Ischemia due to hypovascularity in the "critical zone," metabolic disorders, and degeneration of the rotator cuff tendon are postulated as possible causes. The stages of the disease course and the corresponding treatment recommendations are summarized in the review by Loew et al. [3].

Two fundamental aspects of the arthroscopic treatment of calcifying tendinitis are still the subject of debate:
(1) Does the calcified focus have to be evacuated completely?; and (2) Is reconstruction of the tendon defect necessary following evacuation of the calcified focus?

In a recently published study, Maier et al. investigated the extent to which partial or complete surgical removal of the calcified focus affected the functional outcome [4]. In 82 out of 99 patients, complete removal of the calcified focus was achieved in the course of arthroscopic therapy, while 17 out of 99 patients still had slight calcium residues in the area of the tendon immediately postoperatively. An equally good clinical outcome was achieved in both groups. Any residual deposits still present dissolved spontaneously in the subsequent disease course. However, in our own procedure, we recommend that the majority of the calcium deposit (at least $80 \%$ ) be removed. Furthermore, it should be ensured that no intratendinous calcium deposit remains that has not at least been opened.

The question of whether a tendon suture is necessary following evacuation of the calcified focus is a matter of discussion. In their study, Balke et al. undertook a follow-up sonographic examination of patients 6 years after surgical evacuation of the calcified focus [1]. The authors report a significantly higher risk of tears in the area of the supraspinatus tendon of the operated shoulder than on the contralateral side. This raises the question of whether the repair of a significant tendon defect is worthwhile. Yoo et al. assessed the clinical outcomes following complete removal of calcium deposits with and without rotator cuff tendon repair in 35 consecutive patients [6] and observed that repair yielded good clinical results and earlier pain relief.

Arthroscopic debridement of shoulder calcification can result in excellent functional outcomes and high patient satisfaction. The rotator cuff should be examined for integrity after removal of the calcified focus. If a defect is present in the area of the rotator cuff, this should also be reconstructed. In our own approach, defects in the area of the rotator cuff tendon with a depth of $5 \mathrm{~mm}$ or more are repaired with a side-to-side suture.

\section{Practical conclusion}

\section{- In therapy-refractory calcifying ten- dinitis without evidence of resolution of the calcific deposit (stage II), arthroscopic resection of the calcific deposit is indicated. \\ - If possible, the calcific focus should be completely removed and the result checked intraoperatively by means of fluoroscopy. \\ - In the case of rotator cuff defects, these should be treated by suturing, usually side-to-side suturing.}

\section{Corresponding address}

\section{Marc Schnetzke, MD}

German Joint Centre Heidelberg, ATOS Clinic Heidelberg

Bismarckstraße 9-15, 69115 Heidelberg,

Germany

marc.schnetzke@atos.de

Funding. Open Access funding enabled and organized by Projekt DEAL.

\section{Compliance with ethical guidelines}

Conflict of interest. M. Loew received royalties from Wright/Tornier Inc., which is not related to the subject of this work. S. Lichtenberg is a paid consultant for Arthrex and Exactech and has received royalties from Arthrex, which is not related to the subject of this work. No company had any input into the review, data analysis, or manuscript preparation. M. Schnetzke, his immediate family, and any research foundations with which he is affiliated have not received any financial payments or other benefits from any commercial entity related to the subject of this article. 


\section{Technical Note}

For this article no studies with human participants or animals were performed by any of the authors. All studies performed were in accordance with the ethical standards indicated in each case.

Open Access. This article is licensed under a Creative Commons Attribution 4.0 International License, which permits use, sharing, adaptation, distribution and reproduction in any medium or format, as long as you give appropriate credit to the original author(s) and the source, provide a link to the Creative Commons licence, and indicate if changes were made. The images or other third party material in this article are included in the article's Creative Commons licence, unless indicated otherwise in a credit line to the material. If material is not included in the article's Creative Commons licence and your intended use is not permitted by statutory regulation or exceeds the permitted use, you will need to obtain permission directly from the copyright holder. To view a copy of this licence, visit http://creativecommons.org/licenses/by/4.0/.

\section{References}

1. Balke M, Bielefeld R, Schmidt C, Dedy N, Liem D (2012) Calcifying tendinitis of the shoulder: midterm results after arthroscopic treatment. Am J Sports Med 40(3):657-661. https://doi.org/10. 1177/0363546511430202

2. Gärtner J, Simons B (1990) Analysis of calcific deposits in calcifying tendinitis. Clin Orthop Relat Res 254:111-120

3. Loew M, SchnetzkeM, LichtenbergS (2021)Current treatment concepts of calcifying tendinitis of the shoulder. Obere Extremität. https://doi.org/10. 1007/s11678-020-00620-x

4. Maier D, Jaeger M, Izadpanah K, Bornebusch L, Suedkamp NP, Ogon P (2013) Rotator cuff preservation in arthroscopic treatment of calcific tendinitis. Arthroscopy 29(5):824-831. https:// doi.org/10.1016/j.arthro.2013.01.031

5. Ogon P, Suedkamp NP, Jaeger M, Izadpanah K, Koestler W, Maier D (2009) Prognostic factors in nonoperative therapy for chronic symptomatic calcific tendinitis of the shoulder. Arthritis Rheum 60(10):2978-2984. https://doi.org/10.1002/art. 24845

6. Yoo JC, Park WH, Koh KH, Kim SM (2010) Arthroscopic treatment of chronic calcific tendinitis with complete removal and rotator cuff tendon repair. Knee Surg Sports Traumatol Arthrosc 18(12):1694-1699. https://doi.org/10.1007/ s00167-010-1067-7 